\title{
PHOTOSYNTHESIS IN CERATOPHYLLUM DEMERSUM. CARBON FIXATION RATES IN RELATION TO THE PLANTS' PHYSIOLOGICAL STAGE, AND THE CONTENTS OF CHLOROPHYLL AND NON-STRUCTURAL CARBOHYDRATES
}

\author{
ELLYP.H. BEST
}

(Limnological Institute, Rijksstraatweg 6, Nieuwersluis (U.), The Netherlands)

\section{SUMMARY}

Since the role of the submerged aquatic macrophytes in the carbon cycle of lake Vechten (the Netherlands) is in study, attention is paid to several aspects of their productivity. Ceratophyllum demersum is a predominant macrophytic species in the littoral zone of this lake, occurring mainly from three to five metres depth.

In situ measurements of its photosynthetic rate demonstrated a maximum in spring (May), followed by a distinct decrease early in summer and a second maximum in late summer. The spring maximum of the photosynthetic rate coincided with the maximum increase of plant biomass. Maximum isicmass occurred in early autumn (August-September).

Although insitu measurements pointed to the upper plant portions $(70 \mathrm{~cm})$ as the most important with respect to photosynthetic activity, it was demonstrated under standard experimental conditions that lower portions might be equally active depending on the age of the plant. In the lake, light reduction with depth is one of the major causes in the commonly observed decrease in photosynthetic activity in lower plant parts.

Comparison of the photosynthetic rates in plant tips in situ and under standard experimental conditions indicated that in spring, both water temperature and the chlorophyll content of the plant limit photosynthesis. This was concluded since under experimental conditions (a) photosynthetic rate and chlorophyll content were strongly correlated during the first half of the growing season and (b) higher rates were measured than in situ. In the subsequent stage, however, light and the distribution of non-structural carbohydrates (TNC) in the plant also play an important role.

At the second half the growing season, the lower parts of plants growing in the lake lose gradually their buoyancy, caused by a deteriorating light climate resulting in a decreasing photosynthetic activity. 